\title{
Multi-Variable Control and Optimization Strategy for Domestic Solar-ORC Combined Heat and Power Generation System
}

\author{
Diego Vittorini ${ }^{1, *}$, Alessio Antonini ${ }^{1}$, Roberto Cipollone ${ }^{1}$ and Roberto Carapellucci ${ }^{1}$ \\ ${ }^{1}$ University of L'Aquila, Department of Industrial and Information Engineering and Economics, 67100, L'Aquila, Italy
}

\begin{abstract}
The feasibility of a solar-ORC system for domestic combined heat and power generation (CHP) is deeply affected by both the time-varying ambient conditions (e.g. solar irradiance, temperature, wind speed) and the thermal and electrical load profiles variability of the final application. The definition of a proper control strategy is proven to be a major design-challenge for successful operation of solar-ORC systems, with the main goal of assuring that the thermal power demand - for space heating and Domestic Hot Water (DHW) production - and the electricity needs are simultaneously satisfied. The rising demand for energy-autonomous systems also calls for the inclusion of a storage system within the base-layout, that could assure the electricity demand is properly matched after sunset or in very-low irradiance conditions, such as cloudy days. A comprehensive model accounts for the dynamic of the plant-integrated unit, featuring an ORC-based plant that bottoms a flat plate solar thermal collector: a parametric study is presented, and an off-design analysis is performed to properly assess the energy performance of the system. The heat availability to the ORC heat exchanger is evaluated, based on solar availability, thermal losses in the pipes and plant requirements, in terms of operating temperature and pressures and organic fluid mass flowrate. $\mathrm{R} 245 \mathrm{fa}$ is selected as working fluid in the ORC-section. Sliding vanes machines - expander and pump - are considered as rotary equipment. Flat plate heat exchangers complete the base layout, the analysis accounts for. Due to the need for DHW production, a storage unit for hot water is present, upstream the recovery branch: dependently on the ability the fluid at the collector outlet has to meet the ORC requirements for proper operation (about $110^{\circ} \mathrm{C}$ ), the ORC evaporator is fed and the recovery section enabled. Both continuous and unsteady operation underwent an in-depth analysis, as well as the benefits associated with different discharge times for the storage unit. A dedicated control strategy is defined, dependently on whether the electrical output or the thermal one need to be maximized, and accounts for either a flash or a progressive tank discharge. A virtual platform allowed the setting-up of a pilot plant, for direct performance assessment, in presence of different amounts of tank discharges per day and different lower temperatures at the storage tank.
\end{abstract}

\section{Introduction}

A significant interest has risen in the last years towards low-temperature heat conversion into electric power, via Organic Rankine Cycle-based plants (ORC), in the Building - namely, Residential - sector [1-3]. The increasing sensitivity to the matter of renewable energy generation, along with the need to overcome the limits of conventional renewable technologies in terms of (i) low characteristic conversion efficiencies and (ii) little potential for integration among different technologies for combined heat and power generation (CHP) opens the way to the design and implementation of innovative plant concepts [4-6]. Among them, solar-ORC systems are the best available option for distributed generation, when the heat for conversion into electric power is provided by a low-temperature thermal source, such as the fluid heated by a non-concentrated flat plate solar thermal collector. An extensive scientific literature deals with solar-ORC bottoming concentration solar collectors (CSP) that assure higher temperature levels at the ORC section [7-11] and eventually a higher electric output from the power unit. Nonetheless, the higher costs (both investment, operation and management) and the higher technological complexity, compared to the non-concentrated solar module technology, prevents CSP from succeeding in the Residential sector, incline to meet primarily safety, durability and low maintenance requirements, even in spite of a lower thermodynamic merit [12-15].

Generally speaking, the feasibility of solar-driven CHP systems for domestic application is deeply affected by the time-varying ambient conditions (e.g. solar irradiance, temperature, wind speed) and the thermal load profiles variability of the final application: the combination of the two factors makes it hard to predict the residual thermal energy from DHW production, i.e. the available thermal energy for the ORC unit activation [16-19].

*Corresponding Author: diego.vittorini@univaq.it 
This points out the importance of implementing to the final layout one or multiple buffer vessels for thermal energy storage (TES) to decouple the thermal availability to the power unit from the sun and ambient dynamics and -more importantly- to harvest thermal energy when no-DHW withdrawals take place and providing it for power generation. Besides, the filling-emptying and temperature dynamics of the storage unit are key factors for the proper ORC unit sizing and to define for how long the ORC unit can be operated continuously without affecting the DHW production [20, 21].

The scientific literature already deals with the assessment of the potential of various TES configurations, and accounts for both single- and two-tanks systems [22, 23], various heat-transfer fluids (molten-salt mixtures, eutectic mixtures, phase change materials) [24, 25], direct and indirect storage configurations [26, 27] and mostly refers to solar-ORC systems bottoming CSP, i.e. to a different size and cost scale, with respect to domestic applications. In fact, as the plant scale reduces and an extended steady-state operation is no longer guaranteed, fast response to demand fluctuations and ability to adapt to the daily thermal and electrical profile peaks become key drivers in the plant design. Plus, as the plant is expected to meet cost reduction, fail safe, lean layout requirements, complex TES solutions are no longer an option and the definition of a proper control strategy, for the system as a whole, becomes of the essence.

As such systems need to be often integrated to existing buildings with little available room for components installation, parts downsizing is crucial and reflects on the admissible values of the operating parameters for the plant, such as temperatures, pressures, fluid type and mass flowrates. Consequently, only little leverage on the performance enhancement is available from the optimum selection of fluid type, operating temperatures and pressures. A number of attempts can be retrieved in the scientific literature, ranging from the mainstream approaches - relying on the selection of highly performing fluids [28-30] and proper rotary equipment [31-33] - to more pioneering techniques, such as the enhancement of the heat exchanging sections, particularly in low-temperature small-scale plants with only few $\mathrm{kW}$ electricity production [34-36]: a common feature is the high additional cost required by those improvements and the fact that most of the time it is hardly offset by the gain on the power generation it assures.

In the present paper, a comprehensive model of control strategy is defined for a plant-integrated unit, featuring an ORC-based plant that bottoms a flat plate solar thermal collector: a parametric study is presented, and an off-design analysis is performed to properly assess the energy performance of the system. The heat availability to the ORC heat exchanger is evaluated, based on solar availability, collector thermal dynamics, thermal losses in the pipes and plant requirements, in terms of operating temperature and pressures and organic fluid mass flowrate. R245fa is selected as working fluid in the ORC-section. A volumetric pump and a scroll expander are considered as the rotary equipment. Plate and fins heat exchangers complete the base layout, the analysis accounts for. Due to the need for DHW production, a storage unit for hot water is present, upstream the recovery branch: dependently on the ability the fluid at the collector outlet has to meet the ORC requirements for proper operation (above $90^{\circ} \mathrm{C}$ ), the ORC evaporator is fed and the recovery section enabled. In light of the typically very low characteristic conversion efficiency of ORC-based plants, a large share of the thermal power provided to the organic fluid at the evaporation section is expected to be still available at the expander outlet: the model accounts, then, for the possibility to gather this thermal energy in a low-temperature buffer vessel to assist the system in the primary purpose of DHW production and increase the amount of thermal energy potentially available to electric generation.

Both continuous and unsteady operation underwent an in-depth analysis, as well as the benefits associated with different discharge times for the storage unit. A dedicated control strategy is defined, dependently on whether the electrical output or the thermal one need to be maximized, and accounts for either a flash or a progressive tank discharge. An optimum size of the ORC-unit is defined, based on the TES design characteristics, in order to modulate the thermal and electrical generation during the day with the main advantages of (i) extending the range of operation for the CHP unit to the time of the day when little-to-no irradiance is available, (ii) allowing to match both the electric and thermal demand when they take place with no delay and (iii) in case of over-production of electric power, planning the proper management of battery packs or the sale to the grid when it is more valuable, for financial revenue. A virtual platform allowed the setting-up of a pilot plant, for direct performance assessment, in presence of different amounts of tank discharges per day and different lower temperatures at the storage tank.

\section{Combined Heat and Power System Modeling}

Fig. 1 reports the layout of the single evaporation pressure, subcritical cycle, under investigation. A flat plate solar thermal collector (STC) provides hot water to either a high temperature storage unit (HTT) or directly to the evaporator of a bottoming Organic Rankine Cycle, dependently on the temperature level at which the hot water is available at the collector outlet. A circulation pump allows a water/Glycol (40\%) mixture to flow on the back of the solar collector and no mixing with the water for domestic uses occurs within the tank (active indirect configuration). Among the standard flow configurations for STC applications, a low flow set-up (2-8 g/s water/Glycol per square meter collector area mass flowrate) turns out to be the best fit, as it allows the highest water temperature (i.e. the largest thermal availability at the tank), low pumping requirements and low friction losses. 


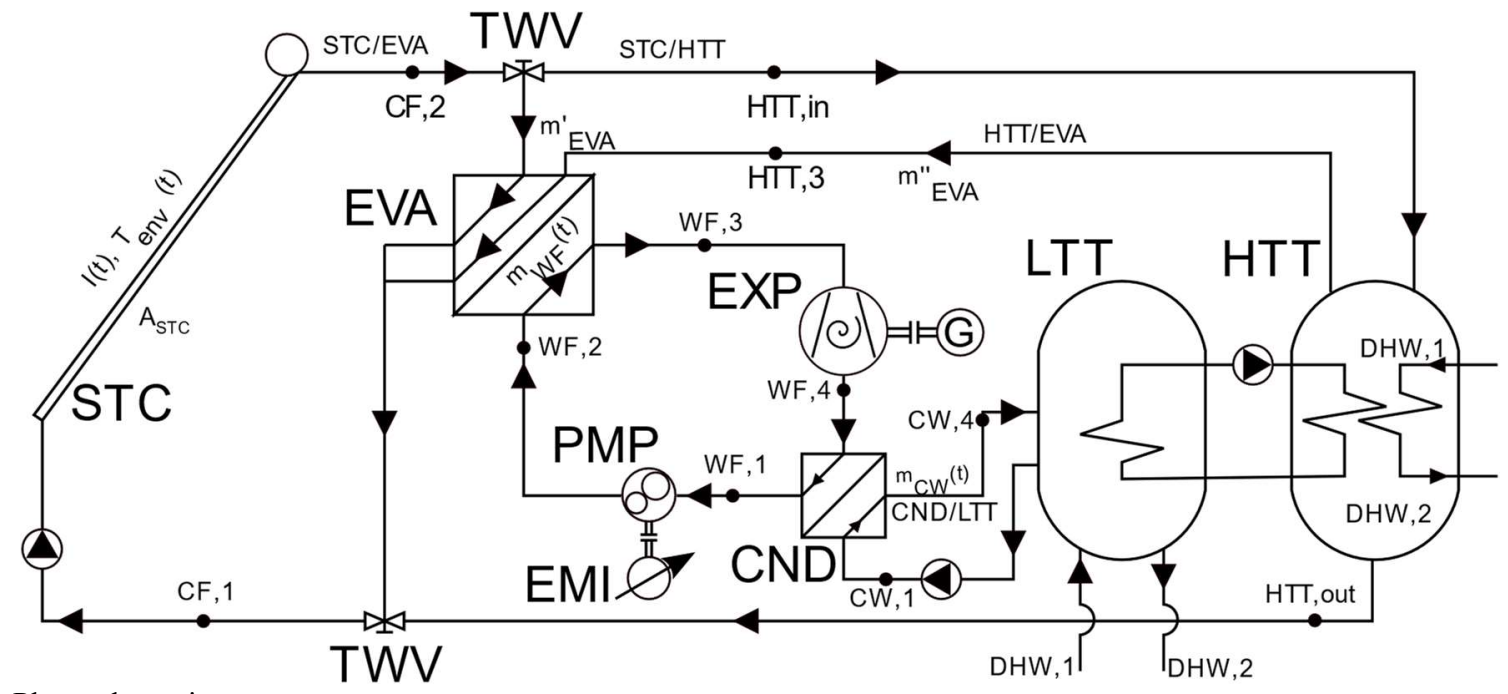

Fig. 1. Plant schematics.

The working fluid (WF, R245fa) is fed by a volumetric pump (PMP) to the evaporation section (EVA). The superheated vapor expands in a scroll expander (EXP) and is cooled down at the condenser (CND), whose cold stream is provided by a low temperature tank (LTT). An electric motor and inverter (EMI) drive the pump and allow the modulation of the working fluid mass flowrate, fed to the evaporator, where a slight superheating occurs (between $5^{\circ} \mathrm{C}$ and $13^{\circ} \mathrm{C}$ ), with characteristic cycle upper pressures in the 6 bar to 11 bar range. The cycle does not feature any recuperative section at the expander outlet, despite the larger thermal efficiency that would assure, by reducing the heat sunk at the condenser.

The reason behind the selection of a scroll expander is the higher characteristic efficiency, with respect to sliding vane technology, at the low mass flowrates that usually characterize low temperature waste heat recovery scenarios. Moreover, scroll expanders are robust towards the quality of the working fluid at inlet, resulting in less constraints on the selection of the superheating degree and eventually in a higher flexibility in thermal profiles matching at the evaporator: as extensively discussed in [34-36] this reflects on a lower loss for irreversibility at the heat exchanger and on a 1-to-3 percentage points gain on the overall energy efficiency of the system. Such an efficiency gain is extremely appealing in small scale systems, where a high back-work ratio (i.e. ratio between the work for pumping and the work gathered at the expander) usually applies and ends up questioning the plant feasibility [34, 37]. These features represent an added value for the ORC system, particularly in presence of an upper thermal source characterized by unsteady heat availability and highly variable thermodynamic conditions like those proper of a domestic solar CHP application (i.e. intermittent solar radiation, influence of ambient conditions, mass flowrate variability due to relatively unpredictable DHW demand profiles).

The input values for main control parameters of the ORC unit are retrieved from NIST RefProp 9.0 (Table 1). Once the pinch point temperature difference at the condenser is selected, the time-varying temperature of the water within the low temperature storage unit governs the heat sink at the condenser. For the configuration in Fig.1, the temperature of the working fluid at the evaporator inlet is then controlled by the thermal balance at the low temperature tank, i.e. the balance between (i) the thermal energy the ORC unit sinks at the condenser and (ii) the heat removal for DHW purposes from the LTT. This calls for a dynamic model of the system and the inclusion of the DHW seasonal profiles to the model-based platform for the assessment of the system energy performance.

Table 1. Thermodynamic cycle parameters and ranges of variation.

\begin{tabular}{lc}
\hline \multicolumn{1}{c}{ Parameter } & Value \\
\hline Working fluid $(\mathrm{WF})$ & $\mathrm{R} 245 \mathrm{fa}$ \\
Subcooling at condenser outlet, $\Delta \mathrm{T}_{\mathrm{sc}}\left({ }^{\circ} \mathrm{C}\right)$ & $1-2$ \\
Approach point temperature difference at EVA inlet, $\Delta \mathrm{T}_{\mathrm{ap}}(\mathrm{K})$ & $5-10$ \\
Limit temperature difference at EVA (properties decay), $\Delta \mathrm{T}_{\mathrm{pd}}(\mathrm{K})$ & 20 \\
Pinch point temperature difference at $\mathrm{CND}\left({ }^{\circ} \mathrm{C}\right)$ & $3-6$ \\
\hline
\end{tabular}

Moreover, the schematics reports the optional connection between the two storage units, that allows the HTT to assist the LTT in case the DHW demand overcomes the heat availability within the low temperature tank. 
The base equations for each component of the solar ORC system are summarized in Table 2, with the heat transfer coefficients, regulating the heat exchange, as in [38-40].

Table 2. Energy balance equation for the analysis of the solar-ORC system main components.

\begin{tabular}{cc}
\hline Section/Component & Equation \\
\hline$\underline{\text { Solar collector }}$ Glass cover & $I_{c, \text { in }}+\dot{Q}_{p, \text { rad }}+\dot{Q}_{p, \text { conv }}-\dot{Q}_{c, \text { rad }}-\dot{Q}_{c, \text { conv }}=M_{c} \cdot c_{p, c} \cdot \frac{d T_{c}}{d t}$ \\
Absorber plate & $I_{p, \text { in }}-\dot{Q}_{p, \text { rad }}-\dot{Q}_{p, \text { conv }}-\dot{Q}_{C F}=M_{p} \cdot c_{p, p} \cdot \frac{d T_{p}}{d t}$ \\
Collector fluid & $\dot{Q}_{C F}=A_{C F} \cdot \lambda_{C F} \cdot\left(T_{p}-T_{C F, 2}\right)=M_{C F} \cdot c_{p, C F} \cdot \frac{d T_{C F}}{d t}$ \\
HTT & $m_{C F} \cdot c_{p, C F} \cdot\left(T_{C F, 2}-T_{C F, 1}\right)+m_{D H W} \cdot c_{p, D H W} \cdot\left(T_{D H W, 1}-T_{D H W, 2}\right)=M_{H T T} \cdot c_{p, H T T} \cdot \frac{d T_{H T T}}{d t}$ \\
LTT & $m_{C W} \cdot c_{p, C W} \cdot\left(T_{C W, 4}-T_{C W, 1}\right)=M_{L T T} \cdot c_{p, L T T} \cdot \frac{d T_{L T T}}{d t}$ \\
ORC & $m_{W F}=m_{C F} \cdot c_{p, C F} \cdot\left(T_{C F, 3}-T_{C F, 2}\right) /\left(h_{W F, 3}-h_{W F, 2}\right)$ \\
CNA & $\dot{Q}_{C N D}=m_{W F} \cdot\left(h_{W F, 4}-h_{W F, 1}\right)$ \\
Net power & $P_{n e t}=\left[m_{W F} \cdot\left(h_{W F, 3}-h_{W F, 4 s}\right) \cdot \eta_{E X P}\right]-\left[m_{W F} \cdot\left(h_{W F, 2 s}-h_{W F, 1}\right) / \eta_{P M P}\right]$ \\
Cycle efficiency & $\eta_{e n}=P_{n e t} / \dot{Q}_{E V A}$
\end{tabular}

\section{Control Strategy}

The year-round simulation of the system was carried out, with reference to a $15 \mathrm{~m}^{2}$ solar thermal collector surface, mounted on a rooftop in the typical climate conditions of central Italy. The limit operating temperature for the solar collector is $150{ }^{\circ} \mathrm{C}$ : shading occurs in case of overheating, in order to prevent thermo-mechanical damage to the system. Based on the technological standard for solar-based DHW generation in the Residential sector, a $150 \mathrm{~L}$ tank is considered as the HTT unit. The LTT has a $50 \mathrm{~L}$ capacity.

The threshold temperature for ORC activation is fixed at $90^{\circ} \mathrm{C}$ : until such limit is reached, the solar collector feeds the HTT unit. As the ORC-activation threshold temperature is reached, the ORC unit is started and the evaporator is fed, either directly with the collector fluid from the STC section or from the HTT section. A controller monitors the water availability for DHW demand fulfillment and prevents any ORC activation that could not be properly matched to the DHW coverage. In ORC-off situations, the HTT entirely sees to the fulfillment of the DHW demand. In ORC-on scenarios, the primary source of hot water for DHW is the LTT, where the heat removed for DHW purposes is continuously re-integrated by the heat sunk at the condenser of the ORC power unit: the additional thermal contribution from the HTT is still available for LTT back-up in presence of peak DHW demand. Fig.2 reports a flowchart of the control strategy of the integrated solar-ORC system. 


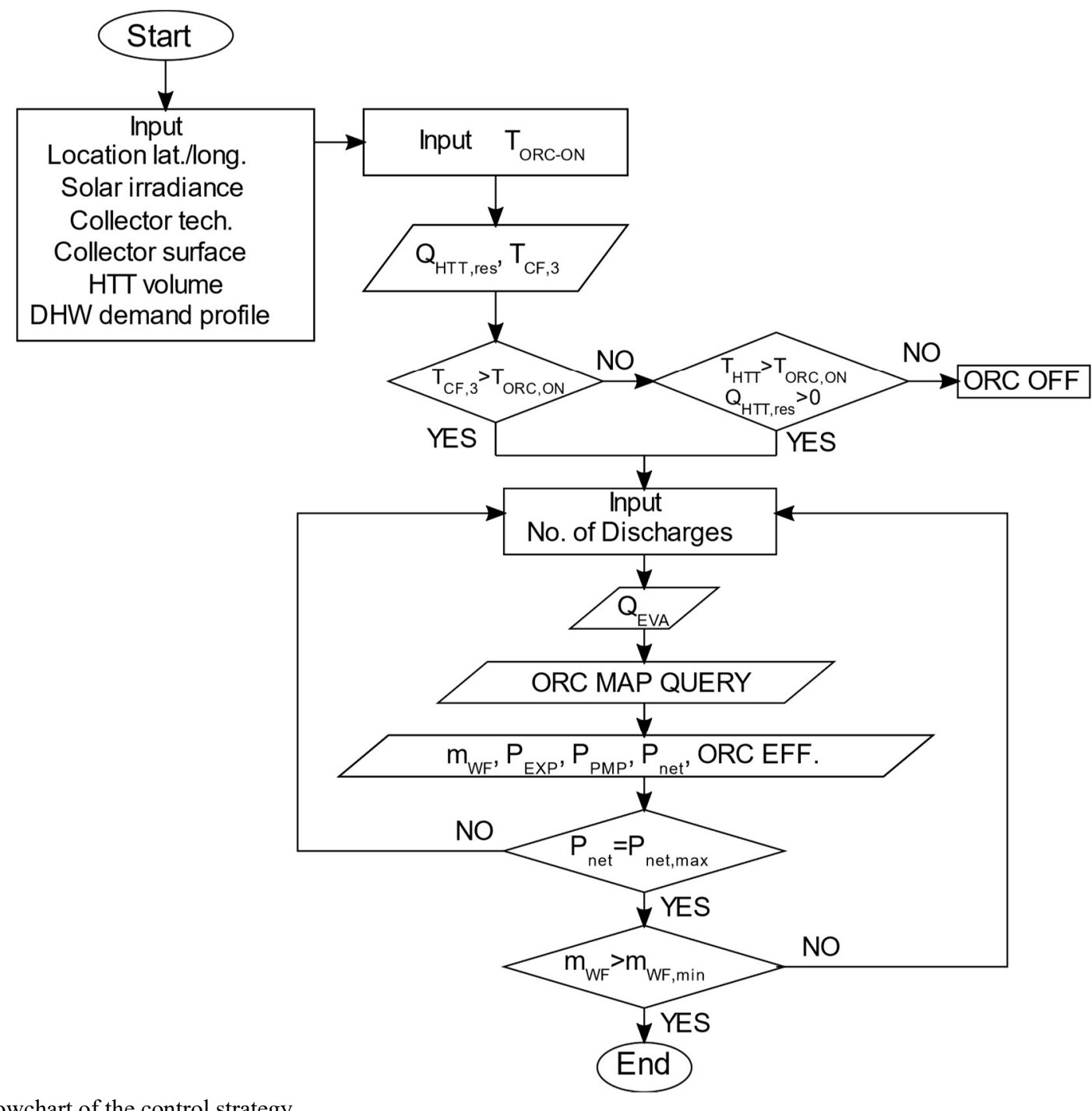

Fig. 2. Flowchart of the control strategy.

Once the solar irradiance of the installation site is assessed, the thermal energy for DHW needs coverage can be easily calculated, based on the collector technology and capture surface. In order to establish whether the power unit turns on, the temperature of the heat transfer fluid at the collector outlet $\left(\mathrm{T}_{\mathrm{CF}, 3}\right)$ needs to be compared to the initialized temperature for ORC-ON (TORC,ON): if the heat transfer at the solar collector results in a temperature of the collector fluid above the threshold for ORC-ON, the evaporator of the power unit is directly fed. Otherwise, a control applies on the temperature at the HTT section: if any thermal energy is left from the fulfillment of DHW demand and the temperature is above the limit for ORC activation, a stream of hot water is sent to the power unit. In case the available thermal energy for the ORC section is provided to the power unit in a single discharge, a daily temperature profile as in Fig. 3 must be expected: severe oscillations are appreciated on the temperature at the collector outlet, i.e. an intermittent operation of the ORC unit. For sake of clarity, Fig. 3 refers to July, $21^{\text {st }}$ and accounts for a $90^{\circ} \mathrm{C} \mathrm{ORC-on} \mathrm{temperature} \mathrm{and} \mathrm{a} 150$ L HTT volume, with 7 ORC activations.

An optimized model of the ORC section is employed to reproduce the operation of the power unit, based on the approach discussed in $[30,34]$, adapted to the situation where a scroll expander is used. The ORC-unit map that comes out is in good agreement with the experimental data in [37], where the potential of an ORC-unit, featuring a scroll expander and a volumetric pump as the rotary equipment, R245fa as the working fluid and performing heat recovery on a $90{ }^{\circ} \mathrm{C}$-to- $120^{\circ} \mathrm{C}$ heat source is considered. Some of the operating points of the ORC unit can be found in Table 3. 


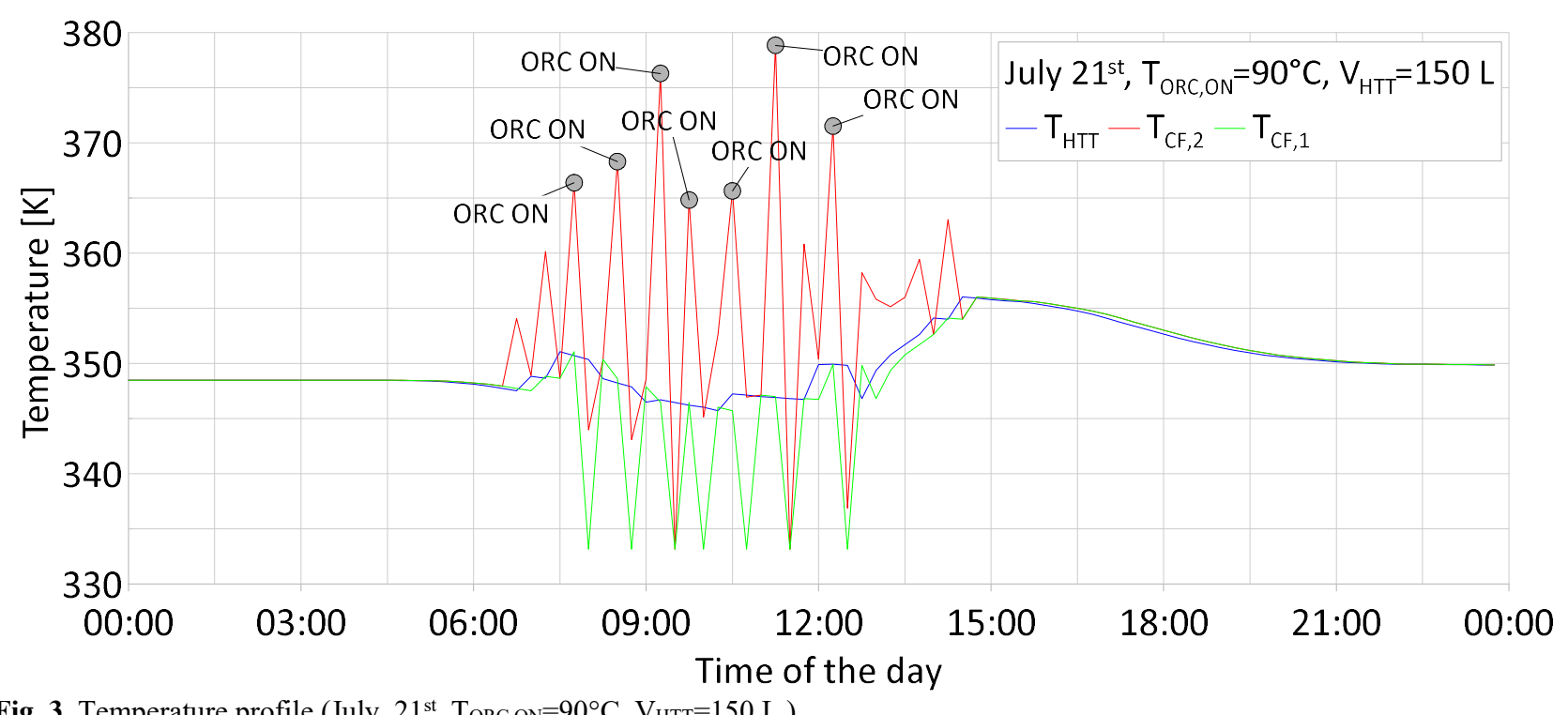

Fig. 3. Temperature profile (July, $\left.21^{\text {st }}, \mathrm{T}_{\mathrm{ORC}, \mathrm{ON}}=90^{\circ} \mathrm{C}, \mathrm{V}_{\mathrm{HTT}}=150 \mathrm{~L}\right)$.

Table 3. ORC unit design points.

\begin{tabular}{ccccccccc}
\hline $\mathrm{T}_{\mathrm{WF}, 3}$ & $\begin{array}{c}\mathrm{m}_{\mathrm{WF}} \\
{\left[{ }^{\circ} \mathrm{C}\right]}\end{array}$ & $\begin{array}{c}\Delta \mathrm{Tg} / \mathrm{s}] \\
{\left[{ }_{\mathrm{SH}} \mathrm{C}\right]}\end{array}$ & $\begin{array}{c}\dot{\mathrm{Q}}_{\mathrm{EVA}} \\
{[\mathrm{kW}]}\end{array}$ & $\begin{array}{c}\mathrm{P}_{\mathrm{EXP}} \\
{[\mathrm{kW}]}\end{array}$ & $\begin{array}{c}\mathrm{P}_{\mathrm{PMP}} \\
{[\mathrm{kW}]}\end{array}$ & $\begin{array}{c}\mathrm{P}_{\text {net }} \\
{[\mathrm{kW}]}\end{array}$ & $\begin{array}{c}\eta_{\mathrm{ORC}} \\
{[\%]}\end{array}$ & $\begin{array}{c}\mathrm{BWR} \\
{[-]}\end{array}$ \\
\hline 80 & 0.035 & 5.0 & 7.4 & 0.450 & 0.113 & 0.337 & 4.55 & 0.251 \\
85 & 0.056 & 5.2 & 11.6 & 0.535 & 0.161 & 0.374 & 3.22 & 0.301 \\
90 & 0.038 & 10.2 & 10.5 & 0.482 & 0.135 & 0.347 & 3.30 & 0.281 \\
95 & 0.062 & 12.0 & 14.3 & 0.550 & 0.187 & 0.363 & 2.54 & 0.340 \\
100 & 0.073 & 6.3 & 18.2 & 0.582 & 0.282 & 0.300 & 1.65 & 0.485 \\
105 & 0.068 & 12.5 & 16.6 & 0.565 & 0.243 & 0.322 & 1.94 & 0.430 \\
\hline
\end{tabular}

It is worth pointing out that as the thermal power at the evaporator increases, the mass flowrate of working fluid in the ORC section increases (Fig. 4a) and the back-work ratio (BWR) gets larger, i.e. a higher power absorption takes place at the pump (Fig. 4b), resulting in a detrimental effect on the ORC energy efficiency (Table 3). For instance, the design point with $7.4 \mathrm{~kW}$ thermal power is associated with a $4.55 \%$ ORC energy efficiency, whereas with $18.2 \mathrm{~kW}$ thermal power (i.e. more than twice the previous value) a $1.65 \%$ ORC efficiency is attainable (i.e. less than half the previous efficiency value). As a general rule, the larger the mass flowrate of working fluid circulated to fully exploit the thermal energy fed at the evaporator, the larger the loss at the pump.

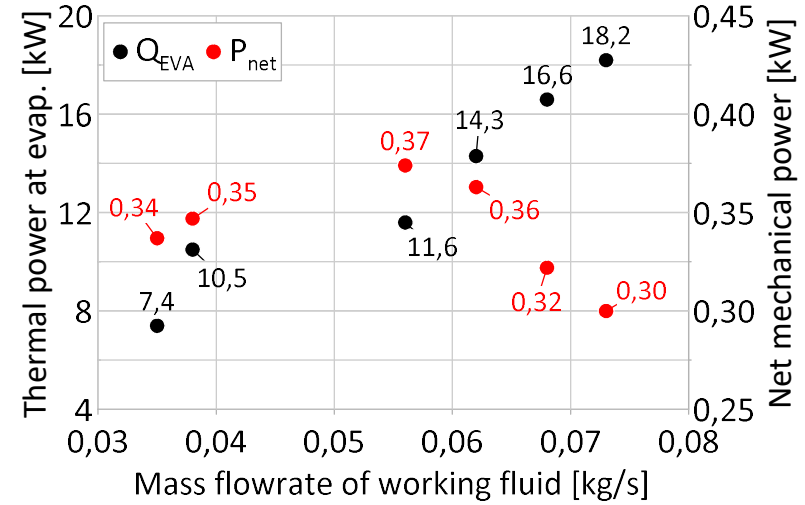

(a)

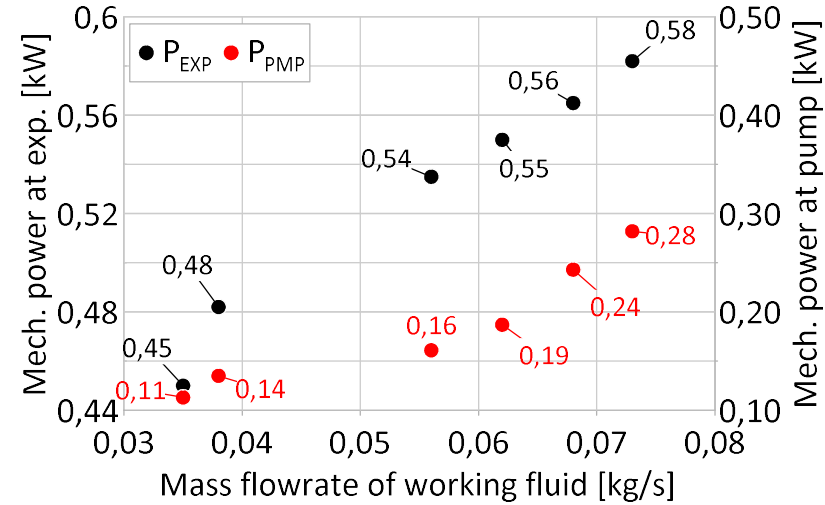

(b)

Fig. 4. ORC unit design points. 


\section{Results and Discussion}

The collector fluid stream that reaches the evaporator is split according to the percentages in Table 4 . For sake of clarity, the results are reported in the form of aggregated data for the summer months: the cumulative mass flowrate to the ORC section between July and September is assessed and then averaged over the total amount of discharges taking place in the same timespan. When the threshold temperature for $\mathrm{ORC}$ activation shifts from $90^{\circ} \mathrm{C}$ to $100^{\circ} \mathrm{C}$, a lower amount of ORC activations takes place, but each stream to the evaporation section is characterized by a larger mass flowrate. In other words, each ORC activation counts on a larger mass of collector fluid at the hot side of the evaporation section, with respect to the situation where a lower ORC-ON temperature applies.

Table 4. ORC unit design points (July-September)

\begin{tabular}{ccccc}
\hline \multirow{2}{*}{$\mathrm{T}_{\mathrm{ORC}, \text { on }}\left[{ }^{\circ} \mathrm{C}\right]$} & \multirow{2}{*}{$\mathrm{V}_{\text {HTt }}[\mathrm{L}]$} & \multicolumn{3}{c}{$\mathrm{m}_{\mathrm{CF}, \mathrm{EVA}}[\mathrm{kg} / \mathrm{s}]$} \\
\cline { 3 - 5 } & & No split & $75 \% / 25 \%$ & $50 \% / 50 \%$ \\
\hline \multirow{2}{*}{90} & 150 & 0.062 & $0.047 / 0.015$ & $0.031 / 0.031$ \\
& 250 & 0.066 & $0.050 / 0.016$ & $0.033 / 0.033$ \\
\hline \multirow{2}{*}{100} & 150 & 0.096 & $0.072 / 0.024$ & $0.048 / 0.048$ \\
& 250 & 0.102 & $0.077 / 0.025$ & $0.051 / 0.051$ \\
\hline
\end{tabular}

As depicted in Fig. 2, in addition to the degrees of freedom associated with the size of the HTT storage unit and the threshold temperature for ORC activation, a further parameter on which the optimization of the energy performance of the system can be performed is the number of discharges to the evaporator, i.e. the modulation of the mass flowrate sent to the recovery section of the ORC cycle: the splitting of the thermal energy fed in two or more streams, results in a lower mass flowrate of working fluid needed at the ORC section, i.e. higher characteristic efficiencies for the cycle itself. A further advantage of such thermal energy modulation is the possibility to avoid an intermittent ORC-unit operation: as highlighted in Fig.3, in a one-time feed scenario, the thermal content associated with the stream of the collector fluid either from the HTT or the STC section directly - is drawn with no margins for further ORC activation, prior the thermal content is restored. In the case of a split-feed, the ORC unit can be continuously operated: one stream is fed to the evaporator, while the one whose envoy to the evaporator is postponed, can be temporarily stored within the HTT section until it is used. If the threshold temperatures for $\mathrm{ORC}-\mathrm{ON}$ are kept around $100^{\circ} \mathrm{C}$, the pressure level required at the high temperature tank to prevent the phase change of the stored water is close to that at the collector-side of the evaporator and thus easily matched. The net recovered mechanical power and the ORC unit efficiency are in Table 5.

Table 5. Net recovered mechanical power and ORC energy efficiency (July-September).

\begin{tabular}{cccccccc}
\hline \multirow{2}{*}{$\mathrm{T}_{\mathrm{ORC}, \text { on }}\left[{ }^{\circ} \mathrm{C}\right]$} & \multirow{2}{*}{$\mathrm{V}_{\text {HTT }}[\mathrm{L}]$} & \multicolumn{3}{c}{$\mathrm{L}_{\text {net }}[\mathrm{kWh}]$} & \multicolumn{3}{c}{ ク ORC $\left.^{2} \%\right]$} \\
\cline { 3 - 8 } & & No split & $75 \% / 25 \%$ & $50 \% / 50 \%$ & No split & $75 \% / 25 \%$ & $50 \% / 50 \%$ \\
\hline \multirow{2}{*}{90} & 150 & 40.3 & 46.8 & 50.0 & 3.81 & 4.42 & 4.73 \\
& 250 & 42.2 & 49.6 & 53.3 & 3.74 & 4.40 & 4.72 \\
\hline \multirow{2}{*}{100} & 150 & 28.5 & 33.1 & 35.4 & 3.68 & 4.27 & 4.27 \\
& 250 & 28.7 & 33.3 & 35.5 & 3.70 & 4.30 & 4.58 \\
\hline
\end{tabular}

The splitting of the thermal energy feed to the evaporator in two streams is always beneficial to the energy performance of the CHP system. For a $150 \mathrm{~L}$ HTT unit and a $90^{\circ} \mathrm{C}$ threshold for ORC activation, an additional $6.5 \mathrm{kWh}(+16 \%)$ mechanical work can be recovered by feeding the evaporator with two streams $(0.047 \mathrm{~kg} / \mathrm{s}$ and $0.015 \mathrm{~kg} / \mathrm{s})$, with respect to no-split scenario, where a single $0.062 \mathrm{~kg} / \mathrm{s}$ stream is provided to the evaporation section for a $40.3 \mathrm{kWh}$ recovered mechanical work. Even larger the gain on the recovered mechanical work when the stream is halved: a cumulative 9.7 $\mathrm{kWh}(+24 \%)$ additional gain can be attained, with two back-to-back $0.031 \mathrm{~kg} / \mathrm{s}$ streams to the power unit. Such gain is appreciated on the energy efficiency as well: it shifts from $3.81 \%$, when no splitting applies, to $4.42 \%$ when the mass flowrate is split into $0.047 \mathrm{~kg} / \mathrm{s}$ and $0.015 \mathrm{~kg} / \mathrm{s}$. An even larger ORC efficiency $(4.73 \%)$ can be attained when the mass flowrate is split in two $0.031 \mathrm{~kg} / \mathrm{s}$ streams.

If the temperature for ORC activation is set to $100^{\circ} \mathrm{C}$, a lower net mechanical work recovered shall be expected: for a 150 L HTT capacity, it drops to cumulative $28.5 \mathrm{kWh}$ between July and September, i.e. $12 \mathrm{kWh}$ less than the value achieved with a $90^{\circ} \mathrm{C}$ threshold. Same goes for the stream-splitting scenario, with cumulative losses up to $15 \mathrm{kWh}$. The reduced number of ORC activations must be held responsible for such lower energy performance: for a $150 \mathrm{~L}$ HTT storage unit, the cumulative thermal energy to the evaporator between July and September tops $1000 \mathrm{kWh}$ (464 ORC activations) for $90^{\circ} \mathrm{C} \mathrm{ORC-ON}$ temperature, $780 \mathrm{kWh}\left(304 \mathrm{ORC}\right.$ activations) for $100^{\circ} \mathrm{C} \mathrm{ORC-ON}$ temperature. This confirms about 
the fact that an optimized control strategy should be oriented towards a higher amount of low mass flowrate discharges to the evaporation section, rather than fewer discharges, with higher characteristic mass flowrates.

\section{Conclusions}

A comprehensive model of control strategy is defined for a domestic solar-ORC CHP plant. The modulation of the thermal energy feed to the ORC-plant assures wide margins for improvement of the energy performance of the power unit and opens the path towards a CHP plant capable of fulfilling both the DHW demand and the electricity needs.

In small scale plants as the ones considered for domestic solar-based CHP applications, the large power absorption by the pump for circulation of the working fluid represents a major side-effect - particularly at higher mass flowrates - and ends up questioning the self-sustainability of the plant and the market success of the technology. Since the working fluid mass flowrate processed in the ORC section depends on the thermal energy provided at the evaporator, the splitting of the mass flowrate of collector fluid at the hot side of the evaporation section represents an interesting option to fulfill better energy performances and a higher net electric power generation. If the available thermal energy for electric generation is fed in multiple streams, the power unit is operated with higher characteristic conversion efficiency and assures a higher energy output than in the no-split scenario. For solar-ORC CHP plant, featuring a commercial $150 \mathrm{~L}$ tank and a $90^{\circ} \mathrm{C} \mathrm{ORC-ON}$ threshold, the additional gain the spitting allows over the months between July and September, tops $9.7 \mathrm{kWh}$, i.e. $+24 \%$ the net mechanical power associated with a no-split configuration. Since analogous values apply to the other months of the year ( $+16 \%$ for January-March, $+17 \%$ for April-June, $+44 \%$ for October-December), the results validity can be safely extended to the year-round operation of the plant. Apart from the energy benefit, the option of modulating the energy feed to the evaporator also prevents the intermittent ORC operation: if no split happens, the thermal energy is entirely drawn from the mass flowrate at the evaporator and no ORC activation can take place before the thermal availability is restored. Close attention must be paid to the temperature set for ORC activation: the higher that is, the lower the amount of possible ORC activations is, i.e. the lower energy output can be attained from the power unit. A shift from $90^{\circ} \mathrm{C}$ to $100^{\circ} \mathrm{C}$ results in a $30 \%$ loss of recovered mechanical work, between April and September; this figure tops $40 \%$ between January and March and 45\% between October and December.

\section{Nomenclature}

\begin{tabular}{cccc}
\hline \multicolumn{4}{c}{ Symbols } \\
\hline A & Area $\left[\mathrm{m}^{2}\right]$ & $\mathrm{P}$ & Power $[\mathrm{kW}]$ \\
$c_{p}$ & Specific heat $[\mathrm{kJ} / \mathrm{kgK}]$ & $\mathrm{Q}$ & Thermal energy $[\mathrm{kJ}]$ \\
$\mathrm{h}$ & Specific enthalpy $[\mathrm{kJ} / \mathrm{kg}]$ & $\dot{Q}$ & Thermal power $[\mathrm{kW}]$ \\
$\mathrm{I}$ & Irradiance $[\mathrm{W}]$ & $\mathrm{T}$ & Temperature $[\mathrm{K}]$ \\
$\mathrm{L}$ & Work $[\mathrm{kJ}]$ & $\mathrm{V}$ & Volume $[\mathrm{L}]$ \\
$\mathrm{M}$ & Mass $[\mathrm{kg}]$ & $\eta$ & Efficiency $[\%]$ \\
$\mathrm{m}$ & Mass flowrate $[\mathrm{kg} / \mathrm{s}]$ & $\lambda$ & Convection coefficient $\left[\mathrm{W} / \mathrm{m}^{2} \mathrm{~K}\right]$ \\
\hline
\end{tabular}

\begin{tabular}{cccc}
\hline & & Acronyms & \\
\hline BWR & Back-work ratio & EXP & Expander \\
CF & Collector fluid & HTT & High temperature tank \\
CND & Condenser & LTT & Low temperature tank \\
CW & Cooling water & PMP & Pump \\
DHW & Domestic hot water & SH & Superheating \\
EMI & Electric motor and inverter & STC & Solar thermal collector \\
EVA & Evaporator & TWV & Three way valve
\end{tabular}


Subscripts

\begin{tabular}{cccc}
\hline ap & Approach point & $\mathrm{p}$ & Absorber plate \\
$\mathrm{c}$ & Cover & $\mathrm{pd}$ & Properties decay \\
conv & Convection & rad & Radiation \\
en & Energy & res & Residual \\
env & Environment & $\mathrm{s}$ & Isentropic \\
in & Inlet & $\mathrm{sc}$ & Subcooling \\
out & outlet & $\mathrm{WF}$ & Working fluid \\
\hline
\end{tabular}

\section{References}

1. J. S. Pereira, J. B. Ribeiro, R. Mendes, G. C. Vaz, J. C. André, “ORC based micro-cogeneration systems for residential application - A state of the art review and current challenges", in Renewable and Sustainable Energy Reviews, 92, (2018), pp. 728-743.

2. D. Mikielewicz, J. Mikielewicz, "A thermodynamic criterion for selection of working fluid for subcritical and supercritical domestic micro CHP”, in Applied Thermal Engineering, 30, (2010), pp. 2357-2362.

3. A. Franco, F. Bellina, "Methods for optimized design and management of CHP systems for district heating networks (DHN)", Energy Conversion and Management, 172, (2018), pp. 21-31.

4. S. Lecompte, H. Huisseune, M. van den Broek, S. De Schampheleire, M. De Paepe, "Part load based thermo-economic optimization of the Organic Rankine Cycle (ORC) applied to a combined heat and power (CHP) system", in Applied Energy, 111, (2013), pp. 871-881.

5. E. S. Barbieri, P. R. Spina, M. Venturini, “Analysis of innovative micro-CHP systems to meet household energy demands”, in Applied Energy, 97, (2012), pp. 723-733.

6. R. Bracco, D. Micheli, R. Petrella, M. Reini, R. Taccani, G. Toniato, “ Micro-Organic Rankine Cycle systems for domestic cogeneration”, in Organic Rankine Cycle (ORC) Power Systems, (2017), pp. 637-668.

7. M. Petrollese, G. Cau, D. Cocco, "The Ottana solar facility: dispatchable power from small-scale CSP plants based on ORC systems", in Renewable Energy, 147, (2020), pp. 2932-2943.

8. Y. He, D. Mei, W. Tao, W. Yang, H. Liu, "Simulation of the parabolic trough solar energy generation system with Organic Rankine Cycle”, in Applied Energy, 97, (2012), pp. 630-641.

9. J. Wang, Z. Yan, P. Zhao, Y. Dai, "Off-design performance analysis of a solar-powered organic Rankine cycle", in Energy Conversion and Management, 80, (2014), pp. 150-157.

10. A. Refiei, R. Loni, G. Najafi, A.Z. Sahin, E. Bellos, "Effect of use of MWCNT/oil nanofluid on the performance of solar organic Rankine cycle", in Energy Reports, 6, (2020), pp. 782-794.

11. M. Petrollese, D. Cocco, "Robust optimization for the preliminary design of solar organic Rankine cycle (ORC) systems", in Energy Conversion and Management, 184, (2019), pp. 338-349.

12. CODE 2 - Cogeneration Observatory and Dissemination Europe. Micro-CHP potential analysis - European level report; (2014).

13. V. R. Patil, V. I. Biradar, R. Shreyas, P. Garg, M. S. Orosz, N.C. Thirumalai, "Techno-economic comparison of solar organic Rankine cycle (ORC) and photovoltaic (PV) systems with energy storage", in Renewable Energy, 113, (2017), pp. 1250-1260.

14. M. Peters, T. S. Schmidt, D. Wiederkehr, M. Schneider, "Shedding light on solar technologies-A techno-economic assessment and its policy implications", in Energy Policy, 39, (2011), pp. 6422-6439.

15. J. M. Rodríguez, D. Sánchez, G. S. Martínez, E. Bennouna, B. Ikken, "Techno-economic assessment of thermal energy storage solutions for a 1MWe CSP-ORC power plant”, in Solar Energy, 140, (2016), pp. 206-218.

16. J. Freeman, K. Hellgardt, C. N. Markides, "Working fluid selection and electrical performance optimisation of a domestic solarORC combined heat and power system for year-round operation in the UK", in Applied Energy, 186, (2017), pp. 291-303.

17. S. Quoilin, M. Orosz, H. Hemond, V. Lemort, "Performance and design optimization of a low-cost solar organic Rankine cycle for remote power generation", in Solar Energy, 85, (2011), pp. 955-966.

18. X.D. Wang, L. Zhao, J.L. Wang, W.Z. Zhang, X.Z. Zhao, W. Wu, "Performance evaluation of a low-temperature solar Rankine cycle system utilizing R245fa", in Solar Energy, 84, (2010), pp. 353-364.

19. M. Santos, J. André, E. Costa, R. Mendes, J. Ribeiro, "Design strategy for component and working fluid selection in a domestic micro-CHP ORC boiler", in Applied Thermal Engineering, 169, (2020).

20. J. Lizana, C. Bordin, T. Rajabloo, "Integration of solar latent heat storage towards optimal small-scale combined heat and power generation by Organic Rankine Cycle", in Journal of Energy Storage, 29, (2020).

21. K. Couvreur, W. Beyne, M. De Paepe, S. Lecompte, "Hot water storage for increased electricity production with organic Rankine cycle from intermittent residual heat sources in the steel industry", in Energy, 200, (2020).

22. D. Vittorini, A. Antonini, R. Cipollone, R. Carapellucci, C. Villante, "Solar Thermal-Based ORC Power Plant for Micro Cogeneration - Performance Analysis and Control Strategy", in Energy Procedia, 148, (2018).

23. B. Nie, Z. Du, B. Zou, Y. Li, Y. Ding, "Performance enhancement of a phase-change-material based thermal energy storage device for air-conditioning applications", in Energy and Buildings, 214, (2020).

24. C. Prieto, L. F. Cabeza, "Thermal energy storage (TES) with phase change materials (PCM) in solar power plants (CSP). Concept and plant performance", in Applied Energy, 254, (2019). 
25. B. Zhao, M. Cheng, C. Liu, Z. Dai, "System-level performance optimization of molten-salt packed-bed thermal energy storage for concentrating solar power", in Applied Energy, 226, (2018).

26. X. Li, E. Xu, S. Song, X. Wang, G. Yuan, "Dynamic simulation of two-tank indirect thermal energy storage system with molten salt, Renewable Energy", 113, (2017), pp. 1311-1319.

27. W. Wang, S. Guo, H. Li, J. Yan, J. Zhao, X. Li, J. Ding, "Experimental study on the direct/indirect contact energy storage container in mobilized thermal energy system (M-TES)", in Applied Energy, 119, (2014).

28. J. Xu, C. Yu, "Critical temperature criterion for selection of working fluids for subcritical pressure Organic Rankine cycles", in Energy, 74, (2014), pp. 719-733.

29. G. Qiu, "Selection of working fluids for micro-CHP systems with ORC, Renewable Energy", 48, (2012), pp. 565-570.

30. D. Vittorini, R. Cipollone, R. Carapellucci, "Enhanced heat exchanger layout for optimum energy performance in solar thermal ORC-based unit", in AIP Conference Proceedings, 2191, (2019).

31. M. Imran, M. Usman, B. Park, D. Lee, "Volumetric expanders for low grade heat and waste heat recovery applications", in Renewable and Sustainable Energy Reviews, 57, (2016), pp. 1090-1109.

32. P. Song, M. Wei, L. Shi, S. N. Danish, C. Ma, "A review of scroll expanders for organic Rankine cycle systems", in Applied Thermal Engineering, 75, (2015), pp. 54-64.

33. F. Fatigati, M. Di Bartolomeo, D. Di Battista, R. Cipollone, “A dual-intake-port technology as a design option for a Sliding Vane Rotary Expander of small-scale ORC-based power units", in Energy Conversion and Management, 209, (2020).

34. D. Vittorini, R. Cipollone, R. Carapellucci, "Enhanced performances of ORC-based units for low grade waste heat recovery via evaporator layout optimization", in Energy Conversion and Management, 197, (2019).

35. M. Wang, Y. Chen, Q. Liu, Z. Yuanyuan, "Thermodynamic and thermo-economic analysis of dual-pressure and single pressure evaporation organic Rankine cycles", in Energy Conversion and Management, 177, (2018), pp. 718-736.

36. T. Li, Z. Zhang, J. Lu, J. Yang, Y. Hu, "Two-stage evaporation strategy to improve system performance for organic Rankine cycle", in Applied Energy, 150, (2015), pp. 323-334.

37. F. Fatigati, M. Di Bartolomeo, D. Di Battista, R. Cipollone, "Experimental characterization of a hermetic scroll expander operating in an ORC-based power unit bottoming an internal combustion engine", in AIP Conference Proceedings 2191, (2019).

38. M. Hamed, A. Fellah, A. Brahim, "Parametric sensitivity studies on the performance of a flat plate solar collector in transient behavior", in Energy Conversion and Management, 78, (2014), pp. 938-947.

39. S. Bouadila, S. Kooli, M. Lazaar, S. Skouri, A. Farhat, "Performance of a new solar air heater with packed-bed latent storage energy for nocturnal use", in Applied Energy, 110, (2013), pp. 267-275.

40. M. Carmona, M. Palacio, "Thermal modelling of a flat plate solar collector with latent heat storage validated with experimental data in outdoor conditions", in Solar Energy, 177, (2019), pp. 620-633. 